\title{
Complications and Management of the Thoracic Endovascular Aortic Repair
}

\author{
Sheena W. Chen, MD ${ }^{1}$ Kyongjune B. Lee, MD ${ }^{1}$ Michael A. Napolitano, MD ${ }^{1}$ \\ Alejandro E. Murillo-Berlioz, MD ${ }^{1}$ Anna P. Sattah, MD $\quad$ Shawn Sarin, MD, MBA ${ }^{1}$ Gregory Trachiotis, MD ${ }^{1}$ \\ ${ }^{1}$ George Washington University Hospital, Washington, District of \\ Columbia \\ 2 Holy Cross Hospital, Silver Spring, Maryland \\ Address for correspondence Gregory Trachiotis, MD, Veterans Affairs \\ Medical Center, Division of Cardiothoracic Surgery and Heart Center, \\ 50 Irving St NW Suite 1A163, Washington, DC 20422 \\ (e-mail: gregory.trachiotis@va.gov).
}

AORTA 2020;8:49-58.

\begin{abstract}
Endovascular treatment in thoracic aortic diseases has increased in use exponentially since Dake and colleagues first described the use of a home-made transluminal endovascular graft on 13 patients with descending thoracic aortic aneurysm at Stanford University in the early 1990s. Thoracic endovascular aneurysm repair (TEVAR) was initially developed for therapy in patients deemed unfit for open surgery. Innovations in endograft engineering design and popularization of endovascular techniques have transformed TEVAR to the predominant treatment choice in elective thoracic aortic repair. The number of TEVARs performed in the United States increased by 600\% from 1998 to 2007, while the total number of thoracic aortic repairs increased by $60 \%$. As larger multicenter trials and metaanalysis studies in the 2000s demonstrate the significant decrease in perioperative morbidity and mortality of TEVAR over open repair, TEVAR became incorporated into standard guidelines. The 2010 American consensus guidelines recommend TEVAR to be "strongly considered" when feasible for patients with degenerative or traumatic aneurysms of the descending thoracic aorta exceeding $5.5 \mathrm{~cm}$, saccular aneurysms, or postoperative pseudoaneurysms. Nowadays, TEVAR is the predominant treatment for degenerative and

Keywords

- thoracic aorta endovascular repair

- endovascular

- aortic disease

- thoracic aorta

- complications

- management

- stent graft traumatic descending thoracic aortic aneurysm repair. Although TEVAR has been shown to have decreased early morbidity and mortality compared with open surgical repair, endovascular manipulation of a diseased aorta with endovascular devices continues to have significant risks. Despite continued advancement in endovascular technique and devices since the first prospective trial examined the complications associated with TEVAR, common complications, two decades later, still include stroke, spinal cord ischemia, device failure, unintentional great vessel coverage, access site complications, and renal injury. In this article, we review common TEVAR complications with some corresponding radiographic imaging and their management.
\end{abstract}

\section{Introduction}

Thoracic endovascular aneurysm repair (TEVAR) was first developed in the early 1990s, and the use of endovascular grafts in thoracic aortic aneurysm repair has since grown to become the mainstay treatment. ${ }^{1-3}$ Prior to TEVAR, thoracic

received

January 14, 2019

accepted after revision

May 24, 2020
DOI https://doi.org/

10.1055/s-0040-1714089. ISSN 2325-4637. aortic repairs were done via open surgery for nearly four decades, which conferred $12 \%$ mortality rate in elective procedures and more than $50 \%$ in emergent open thoracic aortic aneurysm repair. ${ }^{1,4}$ Similar high-mortality and -morbidity rates applied to open abdominal aortic aneurysm repairs prior to the advent of endovascular therapy. ${ }^{5}$
Copyright $\odot 2020$ by Thieme Medical Publishers, Inc., 333 Seventh Avenue, New York, NY 10001, USA. Tel: +1(212) 760-0888.
License terms

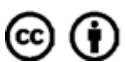




\section{History}

In search for an alternative treatment for patients with significant comorbidities, Parodi et $\mathrm{al}^{6}$ first described the feasibility of abdominal aortic exclusion with an endovascular, stented, Dacron prosthetic graft using retrograde access through the common femoral artery for five patients in 1991. In 1994, Dake et $\mathrm{al}^{1}$ described the first use of a transluminal endovascular graft on the descending thoracic aortic aneurysm in 13 patients. The first TEVAR devices consisted of a customized self-deployable steel Z-stent with the woven Dacron. Each stent was based on each patient's computed tomographic (CT) scan. ${ }^{1}$ Further publications on the effectiveness and safety of TEVAR propelled the creation of commercially available devices, which performed well in clinical trials in the late 1990s. ${ }^{5}$

In September 1999, the U.S. Food and Drug Administration (FDA) approved five endovascular grafts for clinical use in abdominal aortic aneurysm repair, but it was not until 2005 that the FDA approved of the use of stent grafts for TEVAR. ${ }^{5,7}$ Off-label use of stent grafts on descending thoracic aortic aneurysm slowly grew since 1999 . The publication of the Gore TAG trial along with establishing the TEVAR current procedural terminology (CPT) code in 2005 launched TEVAR into mainstream practice (-Fig. 1). ${ }^{4,8-11}$ While there were no TEVAR performed in 1998, 9 years later TEVAR rose to $31 \%$ of all descending thoracic aortic aneurysm repairs when open repairs dropped to $69 \%$ in $2007 .{ }^{4}$ Innovations in endograft engineering design, the popularization of endovascular techniques, and improvement in imaging systems have transformed TEVAR into the first-line treatment for thoracic aortic repair in patients with suitable anatomy. ${ }^{1}$ It is therefore crucial for clinicians to be familiar to the indications, procedure, and devices, a wide range of complications, and the management of potential complications. ${ }^{12}$

\section{Indications for Thoracic Endovascular Aneurysm Repair}

When the FDA approved the use of endovascular grafts for thoracic aortic diseases in 2005, it was limited to repairs of descending thoracic aneurysms, intramural hematoma, and penetrating atherosclerotic ulcer. ${ }^{9,12}$ As TEVAR trials and outcomes studies demonstrated the safety of the procedure and decreased mortality and morbidity compared with open thoracic aortic repair, more patients became candidates for the procedure. $^{2,6}$ In 2012, FDA expanded graft use on traumatic aortic transection, and then in 2013 for all lesions of the descending thoracic aorta, including Type B dissections. ${ }^{12}$

\section{Guidelines}

The 2010 American consensus guidelines recommend that endovascular stent grafting should be "strongly considered when feasible for patients with degenerative or traumatic aneurysms of the descending thoracic aorta exceeding $5.5 \mathrm{~cm}$, saccular aneurysms, or postoperative pseudoaneurysms." ${ }^{13}$ The European guidelines in 2012 recommends TEVAR "when the maximum diameter of the aneurysm exceeds $5.5 \mathrm{~cm}$ or if rapid expansion ( $>5 \mathrm{~mm}$ in 6 months) occurs in patients with symptomatic thoracic aortic aneurysm," taking into account the "patients with increased operative risk" may be considered for a larger aortic diameter threshold. ${ }^{14}$

\section{Preoperative Evaluations}

Despite significant advancement in endovascular techniques and device designs, there are certain TEVAR limitations due to patient anatomy and comorbidities. ${ }^{12}$ While patients with advanced age and multiple comorbidities should undergo standard preoperative clearance, patients who have significant anatomic challenges require further considerations to prevent complications.

\section{Anatomic Considerations}

Imaging assessment is crucial in preoperative planning. After obtaining computed tomography angiography (CTA) with $\leq 1 \mathrm{~mm}$ cuts from the supra-aortic vessels to the common femoral arteries, the use of reconstructive software for threedimensional (3D) image rendering is recommended. ${ }^{10}$ This allows for detailed assessment of the landing zones, tortuosity,

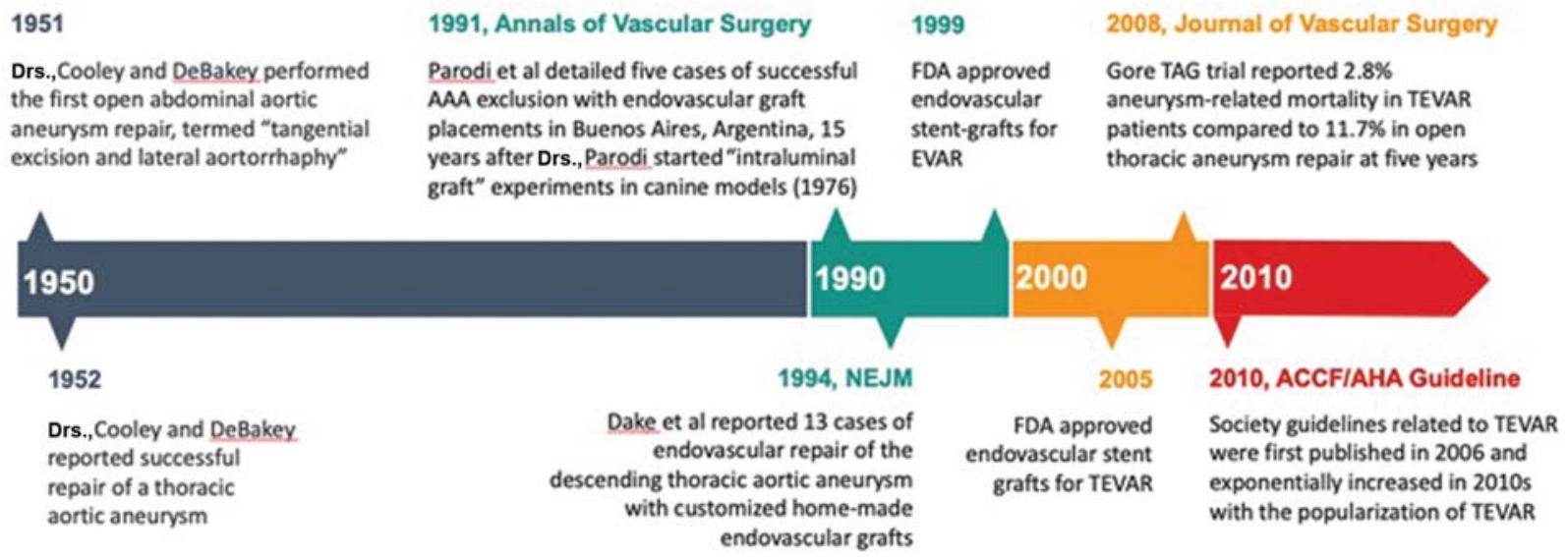

Fig. 1 Chronological timeline of the history of thoracic aneurysm repair. FDA, Food and Drug Administration; TEVAR, thoracic endovascular aneurysm repair. 
angulation, coverage length, diameter of the aneurysm, involvement of the left subclavian artery, intraluminal thrombus, wall calcification, and access site. ${ }^{10}$

A landing zone typically requires a minimum of $20 \mathrm{~mm}$ of healthy aortic wall, proximally and distally. ${ }^{9,10,12}$ The landing zone inner wall diameter is ideally between 16 and $42 \mathrm{~mm}$, based on the current available device dimensions, and it is recommended to use 10 to $20 \%$ oversized grafts to ensure a complete seal and to prevent retrograde aortic dissection. ${ }^{10}$ Insufficient proximal landing zone remains challenging for short proximal neck or significant angulation of the aortic arch near the take-off of the left subclavian artery (LSA). ${ }^{10,12}$ Techniques, such as hybrid repair with debranching, chimneys, fenestrations and branches, or scallop can be considered. ${ }^{10}$ Recently, 3D printed aortic grafts based on preoperative CTA allows for physician-modified fenestrated graft designed for each patient's anatomy, especially in those with poor or insufficient landing zones. ${ }^{14}$ Customization of graft design in the future may eventually reduce the difficulty in managing insufficient landing zones.

Access site navigation remains a challenge especially in patients with significant peripheral vascular disease or with tortuous iliac vessels. ${ }^{10,12}$ Techniques such as balloon angioplasty can treat stenosis of the iliac arteries. Brachiofemoral through-and-through guidewire techniques can assist graft advancement in tortuous arteries. Retroperitoneal access or iliac conduits can be used to bypass small or occlusive arteries. ${ }^{10}$ Other patient factors that should be considered include prior vascular surgeries in the iliofemoral region, but the only major contraindications to TEVAR are current infections at the surgical sites or allergies to the material used in endovascular grafts, for example, patients with known metal allergy might need confirmatory allergy testing to specific metals or need endografts free of the patients' known allergen, commonly nickel. ${ }^{14,15}$

\section{Outcomes and Complications}

TEVAR has been shown to have early decrease in perioperative mortality and morbidities; however, studies have not demonstrated evidence for superior long-term outcome over open thoracic aneurysm repair. ${ }^{9,10,12}$

A multicenter prospective trial using the GORE TAG Thoracic Endograft in 140 patients from 1999 to 2001 showed a significantly lower rate of spinal cord ischemia, respiratory failure, renal insufficiency, shorter hospital stay, and shorter intensive care unit (ICU) stay in the TEVAR group compared with the open repair group. ${ }^{8}$ Although there were three reinterventions in the TEVAR group compared with none in the open group, there was no difference in the overall mortality at 2 years. ${ }^{2}$

A meta-analysis review published in 2010 concluded that TEVAR reduced early mortality within 30 days, paraplegia, cardiac complications, transfusions, bleeding that required reoperation, renal dysfunction, pneumonia, and length of stay (LOS). ${ }^{16}$ However, there was no significant difference in stroke, myocardial infarction (MI), aortic reintervention, or mortality beyond 1 year. ${ }^{16}$
Table 1 List of TEVAR complications discussed in this article

\begin{tabular}{|l|}
\hline Complications of TEVAR \\
\hline Spinal cord ischemia \\
\hline Stroke \\
\hline Endoleaks \\
\hline Endograft collapse \\
\hline Vascular access and device delivery injuries \\
\hline Renal failure \\
\hline
\end{tabular}

Abbreviation: TEVAR, thoracic endovascular aneurysm repair.

Several studies report favorable long-term outcomes for TEVAR. A single institution 11-year outcomes study in 579 patients between 2004 and 2015 reports that overall survival and aorta-specific survival at 11 years were 45.7 and $96.2 \%$, respectively. ${ }^{17}$ Of the 14 patients (7.3\%) who required endovascular reintervention, 10 patients had Type I endoleak, two had Type II endoleak, and two had Type III endoleak. ${ }^{17}$ There was no report of device failure. Unfortunately, as of yet, there have not been any recent meta-analysis on the long-term device durability for TEVAR.

Despite advancement in techniques and devices in the last two decades, the common complications of TEVAR have not changed significantly (-Table 1). ${ }^{12,14}$ They include spinal cord ischemia, stroke, endoleaks, access site complications, guidewire injuries, retrograde dissections, renal injury, unintentional great vessel coverage, aortoesophageal and aortobronchial fistulas, and device failure. ${ }^{9,12,14}$

\section{Spinal Cord Ischemia}

\section{Pathophysiology}

Paraplegia has been a dreaded complication since the early age of TEVAR, and its rate has not declined despite advancement in techniques and devices. ${ }^{3,9,10,14}$ Although TEVAR has proven to be superior to the open surgical repair in many scenarios, it shares a similar rate of spinal cord ischemia (SCI) between 2 and $10 \%^{3,9,10,14,18-20}$ Spinal circulation has become better understood over the years; the widely accepted pathophysiology behind $\mathrm{SCI}$ is from cellular damage from inadequate collateral blood supply to the spinal cord from decrease in blood flow or possible atheroembolism of aortic plaques via segmental arteries that supply the spinal cord. ${ }^{10,20}$ In addition to the artery of Adamkiewicz, there is a collateral network of blood supply from adjacent lumbar muscles and the anterior spinal cord artery, including the lumbar, intercostal, subclavian, vertebral, and hypogastric arteries. ${ }^{10,21}$ Although much controversy exists regarding the optimal preventative methods and treatment for SCI, the main strategies aim to increase the mean arterial pressure (MAP) and placing a lumbar drain to drain cerebrospinal fluid (CSF) to optimize perfusion of the spinal cord. ${ }^{20,22,23}$

\section{Risk Factors}

Risk factors for SCI can be classified by patient-related or surgery-related factors. ${ }^{20}$ The patient-related factors, 


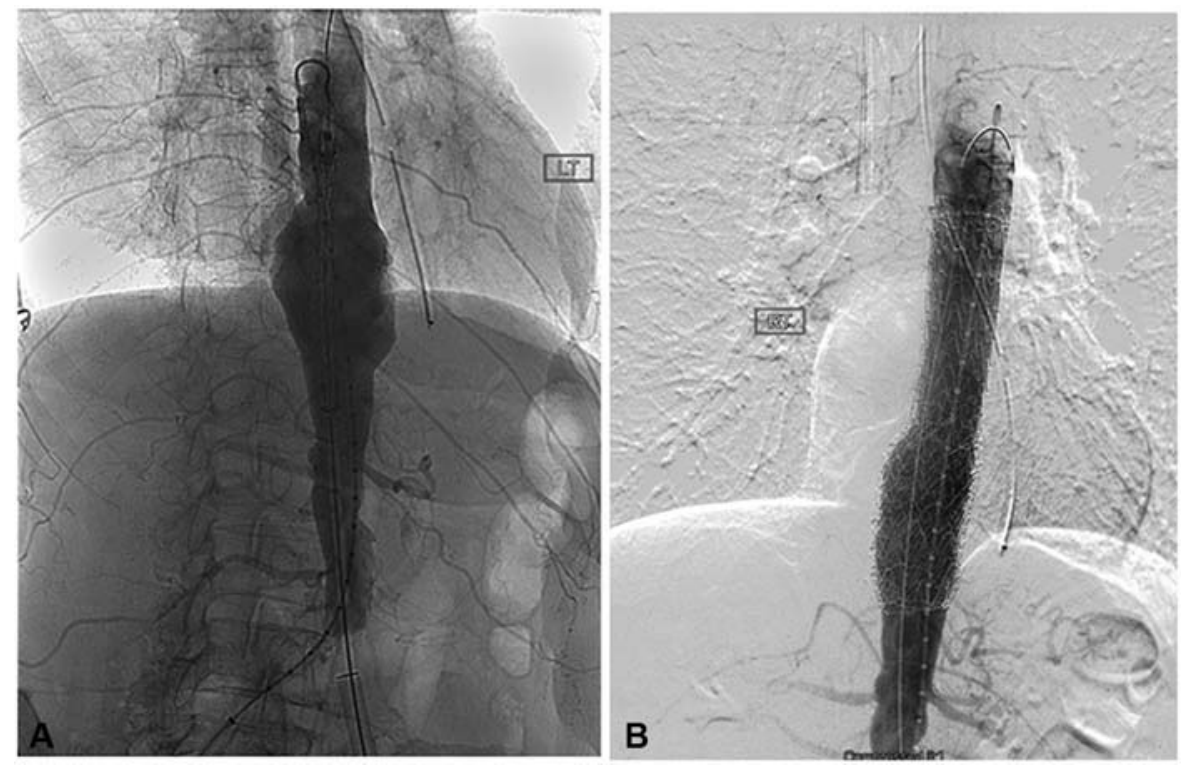

Fig. 2 (A) Conventional angiography of the aorta shows an aneurysm at the level of the diaphragm. (B) Note the occlusion of radicular arteries upon deployment of the endograft on this digital subtraction image.

including degenerative aneurysms, advanced age, chronic obstructive pulmonary disease (COPD), hypertension (HTN), and renal failure, contribute to the extent of aneurysm severity or increased chance of perioperative hypotension. ${ }^{24-28}$ The surgery-related risk factors involve any intervention that would decrease spinal collateral flow, especially in the lumbar region where there is less robust collateralization. These include excessive blood loss, coverage of LSA or hypogastric artery, coverage of greater than two arteries that supply the collateral network, longer procedure duration, and total aortic coverage greater than $200 \mathrm{~mm}$ (-Fig. 2). ${ }^{26,28-30}$

\section{Prevention and Management}

There are numerous proposed neuroprotective strategies in the literature. ${ }^{10}$ General concepts include enhancing spinal cord perfusion, pharmacologic neuroprotection, and reducing metabolic and oxygen requirements. ${ }^{10}$

There are many strategies to enhance spinal cord perfusion. First, it is recommended to maintain an elevated intraoperative and postoperative MAP between 85 and $100 \mathrm{~mm}$ Hg. ${ }^{10,31}$ For patients who suffer SCI, MAP greater than $90 \mathrm{~mm}$ $\mathrm{Hg}$ is preferred. ${ }^{29}$ Second, clinicians should be mindful of the extent of graft coverage to preserve as much collateral blood supplies as possible. ${ }^{10,31}$ Third, pre-TEVAR LSA revascularization has been shown to decrease the risk of SCI if LSA is likely to be covered by graft. ${ }^{31}$ Fourth, CSF drainage improves spinal cord perfusion by decreasing intrathecal pressure and increasing the pressure gradient. ${ }^{23,31-33}$ Although a meta-analysis showed no benefit in prophylactic CSF drainage in TEVAR patients, ${ }^{33}$ some studies show evidence for prophylactic CSF drainage in patients with prior abdominal aortic aneurysm (AAA) repair, extensive thoracic aortic coverage, and subclavian artery coverage without revascularization. ${ }^{31-35}$ Lastly, clinicians are investigating novel procedural strategies to induce remodeling of the spinal collateral blood flow with controlled partial ischemia. ${ }^{10}$ Studies have shown the benefit of performing a staged repair in patients undergoing extensive TEVAR, especially in hybrid thoracoabdominal aortic aneurysm repairs, to stimulate collateral arterial supply remodeling after initial partial coverage and then complete the full graft coverage at a later time. ${ }^{10,36}$ This may be considered when covering a large segment greater than $30 \mathrm{~cm} .{ }^{30}$ Other studies have used minimally invasive segmental artery coil embolization (MISACE) to stimulate arteriogenesis around the embolized segmental arteries that perfuse the spinal cord prior to the TEVAR procedure. This is thought to precondition the spinal cord for ischemia during the actual repair. ${ }^{28}$ An ongoing clinical trial-Paraplegia Prevention in Aortic Aneurysm Repair by Thoracoabdominal Staging with "Minimally-Invasive Segmental Artery Coil-Embolization": A Randomized Controlled Multicenter Trial (PAPA-ARTIS)" that involves multiple medical centers in Europe and United States-is evaluating the effectiveness of MISACE. The temporary aneurysm sac perfusion procedure that prevents immediate aneurysm sac thrombosis is another potential solution to the problem of SCI in TEVAR. It was proven successful in a small clinical trial, but more studies are required to determine the feasibility. ${ }^{37}$

Other medical adjunct measurements have also been popular in practice. ${ }^{10,19}$ Pharmacologic agents, such as intrathecal papaverine injection that induces vasodilation around the spinal cord circulation, have been shown to reduce the rate of paraplegia in a prospective randomized study. ${ }^{38}$ A study of combined neuroprotective protocol of perioperative naloxone, intraoperative mannitol, and steroids along with mild hypothermia reports a slightly reduced rate of SCI $(0.65 \%$; 1 out of 154 patients). ${ }^{19}$ In theory, naloxone reduces the release of neurotransmitter, mannitol reduces spinal cord swelling, steroids have a stabilization effect on neural cell membranes, and mild hypothermia lowers the metabolic and oxygen requirement; altogether increasing the body ischemic tolerance. ${ }^{19}$ It is unclear if each of the elements has a significant effect in preventing SCI. 


\section{Stroke}

Stroke continues to be a major complication of TEVAR, with reported incidences of stroke after TEVAR ranging from 1.2 to $8.2 \%{ }^{10,14,26,39}$ TEVAR eliminates the embolism risk from aortic cross-clamping or cardiopulmonary bypass, but TEVAR can cause embolization from the manipulation of a diseased aortic arch and great vessels with wires and catheters. ${ }^{10,14}$ Risk factors for embolic stroke include acute aortic dissections, large atherosclerotic burden of the aortic arch, HTN, and known cerebrovascular disease. ${ }^{10,40}$ Besides embolic events, reduction in global cerebral perfusion is another main cause of stroke perioperatively. ${ }^{14}$ The risk increases with increased aortic coverage, occlusion or coverage of the LSA, perioperative hypotension, and prolonged surgery. ${ }^{10,12,15,40}$

To prevent perioperative stroke, some studies propose screening patients for a dominant left vertebral artery with brain CTA or magnetic resonance imaging (MRI), especially in patients with significant comorbidities. ${ }^{10,12,41}$ Feezor et $\mathrm{al}^{39}$ reported a decreased stroke rate after TEVAR with preoperative LSA revascularization. On the other hand, a meta-analysis showed no significant difference in neurologic complications or mortality with preoperative LSA revascularization. ${ }^{41} \mathrm{New}$ devices, such as fenestrated grafts, appear to be promising solutions to prevent occluding branches of the aortic arch, but more studies are needed to support the benefit of these devices. ${ }^{42,43}$

When proximal endograft coverage is needed and causes occlusion to the great vessels branching off of the aorta (-Fig. 3B), pre-TEVAR revascularization, in this case, a series of extra-anatomical bypasses, is required to maintain cerebral blood flow. - Fig. $3 \mathrm{C}$ shows perfusion of the carotid artery through the extra-anatomic bypass.

\section{Endoleaks}

Endoleak is defined by the persistence of blood flow and pressurization of the diseased aortic segment that is supposed to be excluded by the endograft. ${ }^{43}$ Since the term "endoleak" was first published in 1997, the incidence of endoleak decreased from $20-50 \%$ to $5-10 \%$ with modern devices. ${ }^{12,44-48}$ Endoleaks are classified according to the mechanism of persistent pressurization of aneurysmal sac. Each type of endoleak corresponds with a different management strategy (-Table 2). ${ }^{48}$ Endovascular intervention remains the mainstay of therapy for endoleak repair. Treatments aim to either bridge the endoleak defect or to embolize the endoleak source such as a lumbar artery. ${ }^{48}$ Open surgical repair sometimes is necessary when endovascular techniques fail.

Type I and III endoleaks are relatively high-pressure systems due to continued communication between systemic circulation and the aneurysm. ${ }^{48,49}$ Therefore, Type I and III endoleaks have a greater risk of rupture and require intervention. ${ }^{48}$ Type I endoleaks can occur immediately after graft placement or develop over time, and they are commonly detected via contrast-enhanced CT on postoperative follow-up imaging. ${ }^{12,48}$ Delayed onset of Type I endoleak can be associated with short or angulated proximal aortic neck anatomy that prevents a proper seal. ${ }^{50}$ Endovascular therapies aim to create an effective seal between the stent graft and the aorta. ${ }^{51}$ Novel techniques such as EndoAnchors used in the ANCHOR study demonstrated effectiveness as a prophylaxis to prevent Type Ia endoleak; however, EndoAnchors as the sole endovascular treatment for Type Ia endoleak leaves $34 \%$ of patients with persistent endoleak. ${ }^{51}$ If mechanical approaches fail, there are several commercially available substances to embolize the endoleak. ${ }^{48}$ Type III endoleak is usually caused by insufficient
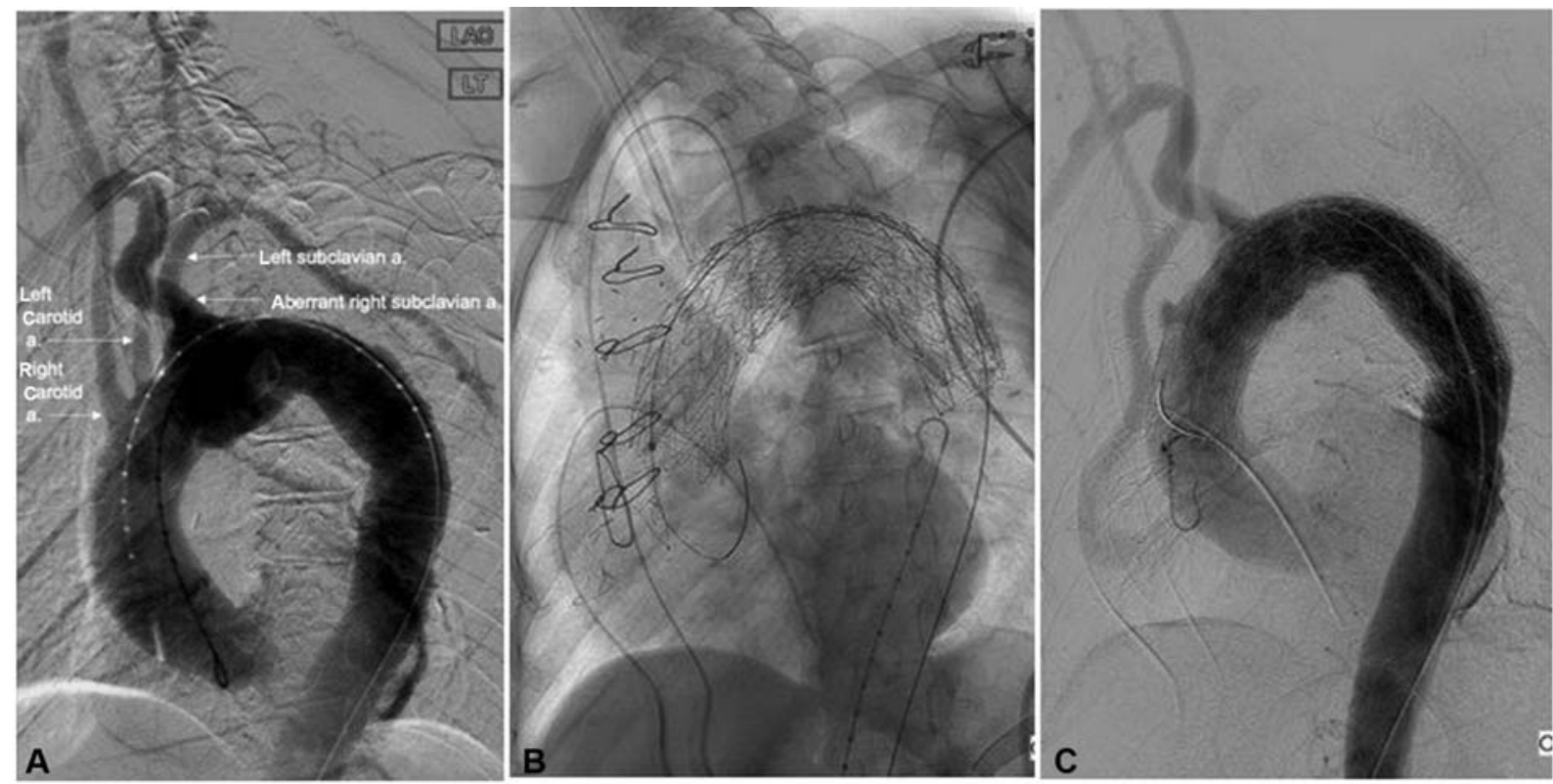

Fig. 3 Endograft covering (A) aortogram prior to deploying thoracic aortic stent shows an aberrant right subclavian artery originating distal to the left subclavian artery, along with the right and left carotid arteries (labeled with arrows). Note that, this is different from the most common aortic arch anatomy with three great vessels originating from the aortic arch: brachiocephalic, left common carotid, and left subclavian arteries. (B) The thoracic aortic stent covering the origin of all three vessels after placement. (C) Aortogram after pre-TEVAR extra-anatomic bypass from the root of the aorta to the left carotid artery. a., artery; TEVAR, thoracic endovascular aneurysm repair. 
Table 2 Summary of different types of endoleaks with respective definitions and treatment modalities when repair is indicated

\begin{tabular}{|l|l|l|}
\hline Type & Mechanism & Therapy \\
\hline I & $\begin{array}{l}\text { Sealing failure at one of the attachment sites of the graft to the } \\
\text { vessel. la: proximal leak; Ib: distal leak }\end{array}$ & Endovascular repair \\
\hline II & Retrograde flow through collateral vessels into the perigraft space & Observation vs. endovascular repair \\
\hline III & $\begin{array}{l}\text { Device failure due to dysfunction of the components of a modular } \\
\text { graft (IIla) or in the fabric of the graft (IIIb) }\end{array}$ & Endovascular repair (very rare) \\
\hline IV & Passage of blood or fluid into the aneurysmal sac as a result of graft porosity & Endovascular repair (very rare) \\
\hline V & $\begin{array}{l}\text { Continued aneurysm sac expansion without a demonstrable } \\
\text { leak by an imaging modality }\end{array}$ & Observation vs. endovascular repair \\
\hline
\end{tabular}

overlapping between graft components, which is treated with additional devices to seal the defect. ${ }^{48}$

Type II endoleak is the most common type, accounting for approximately $75 \%$ of all endoleaks in the EVAR literature, and its treatment is variable. ${ }^{47}$ Most of the Type II endoleaks will remain stable, decrease in size, or spontaneously thrombose over time. ${ }^{45}$ Treatment is required if symptoms persist or if an aneurysm expands, frequently with endovascular embolization of the supplying blood vessel. ${ }^{10,12,52}$

With the advancement in graft material, Type III and IV endoleaks have become very uncommon and are usually treated with additional stent grafts if needed. ${ }^{52}$ Type $\mathrm{V}$ endoleaks are more elusive. Some authors have reported successful outcomes converting polytetrafluoroethylene grafts to polyester grafts, implanting proximal and distal extension cuffs, aspiration, and laparoscopic fenestration of the aneurysm sac. ${ }^{53,54}$ Most cases of Type V endoleaks with expansion of the aortic aneurysm require open repairs.

\section{Endograft Collapse}

Stent-graft collapse after TEVAR is a rare complication that has been reported in a few cases with predominantly young patients who were treated for traumatic aortic dissection. ${ }^{10,12,54}$ Muhs et al ${ }^{55}$ concluded that smaller distal aortic diameter and minimal intragraft aortic diameter are risk factors for endograft collapse. Kasirajan et $\mathrm{al}^{56}$ reviewed all cases of TAG device collapse (compression or infolding) from 1998 to 2008 and concluded that most of the cases were caused by off-label use in trauma patients and endograft oversizing, where endografts with diameters 15 to $30 \%$ larger than the intraluminal diameter are placed. The incidence of stent collapse is rare but with serious morbidity and mortality that require emergent TEVAR or open repair. ${ }^{12,57,58}$

\section{Vascular Access and Device Delivery Injuries}

Although TEVAR has revolutionized the treatment of aortic disease, vascular access and device delivery are still the limiting factors for some patients. ${ }^{10}$ Devices can be delivered in a retrograde or anterograde fashion. Both approaches have several options and techniques. ${ }^{59-61}$

TEVAR devices are most commonly delivered in a retrograde manner via the iliofemoral vessels. ${ }^{10,12}$ The iliofemoral access is dependent on sheath size, average iliac artery diameter, iliofemoral morphology, and preoperative anklebrachial index. ${ }^{62}$ Early complications include arterial dissection (-Fig. 4), iliac artery rupture, arterial perforation (-Fig. 5), and distal thromboemboli (-Fig. 6). ${ }^{39}$ Arterial disruption can cause severe retroperitoneal hemorrhage and require rapid conversion to open repair, and retrograde arterial dissection can cause mesenteric or renal ischemia ( - Fig. 7) that require emergent endovascular or open repair. The most common late complication was lower limb ischemia that needs immediate medical treatment and potentially surgical bypass. ${ }^{39}$

For patients with vascular occlusive diseases or other factors that prohibit the retrograde delivery of the stent graft devices, an antegrade approach may be feasible. ${ }^{12}$

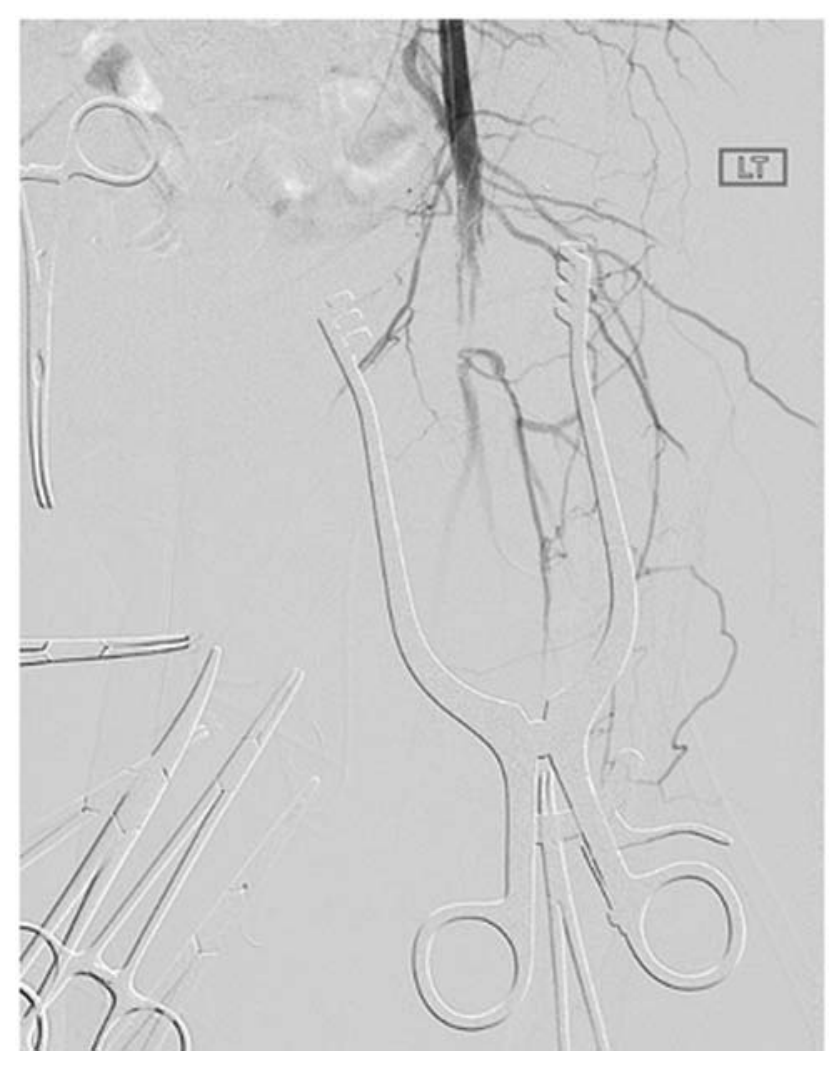

Fig. 4 Dissection of the iliac artery at the access site. 


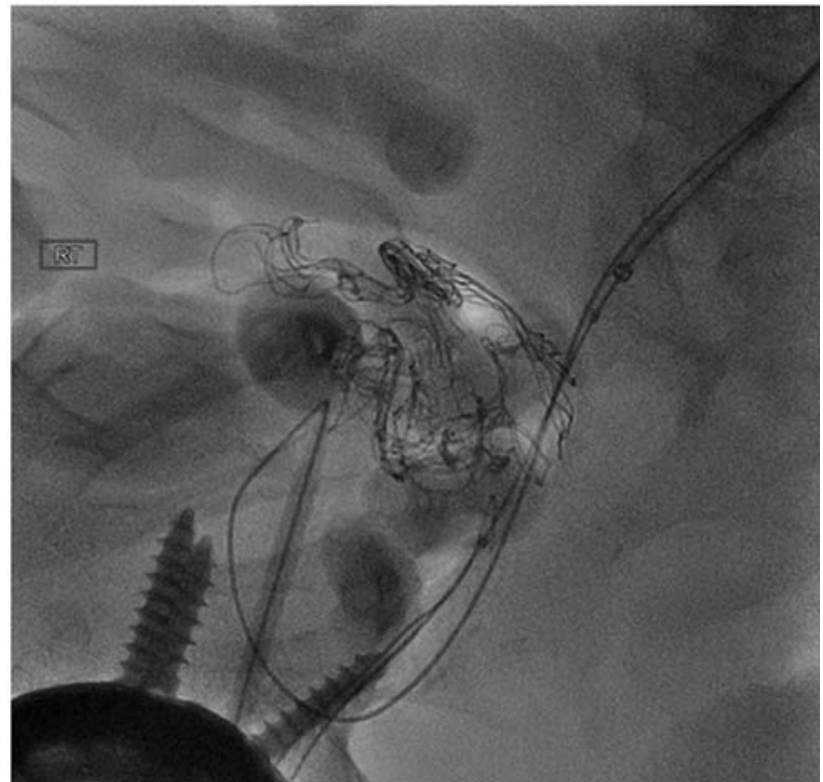

Fig. 5 Example of guidewire injury. Guidewire is shown to have perforated the vessels, demonstrated with contrast extravasation.

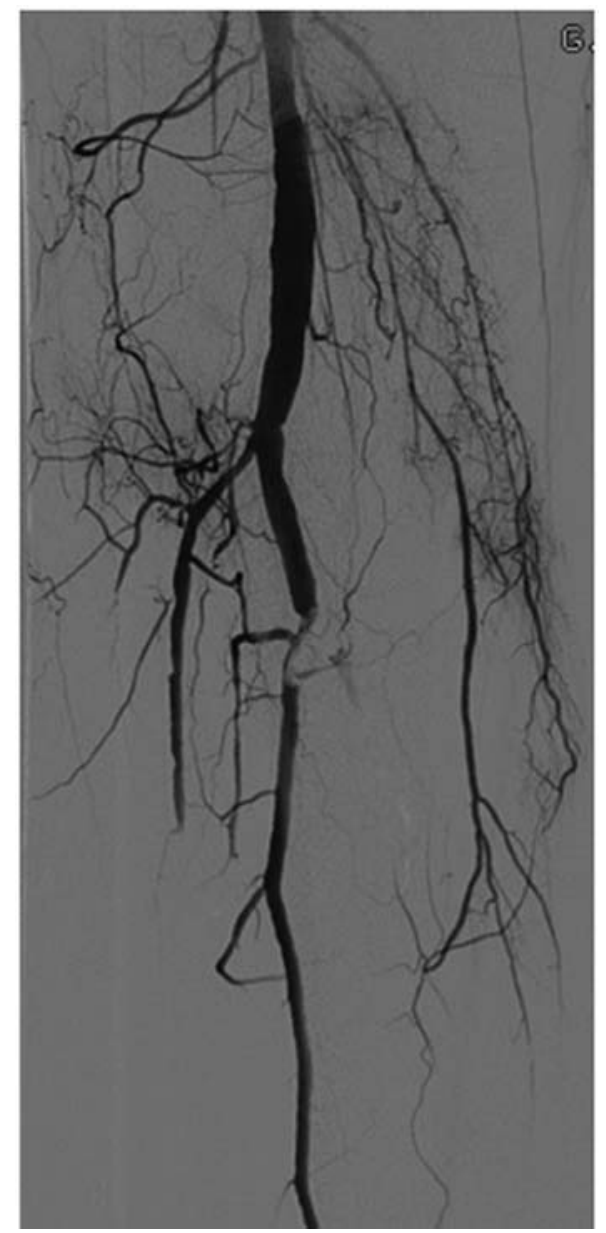

Fig. 6 Distal embolization to tibioperoneal trunk following a thoracic endovascular aneurysm repair.

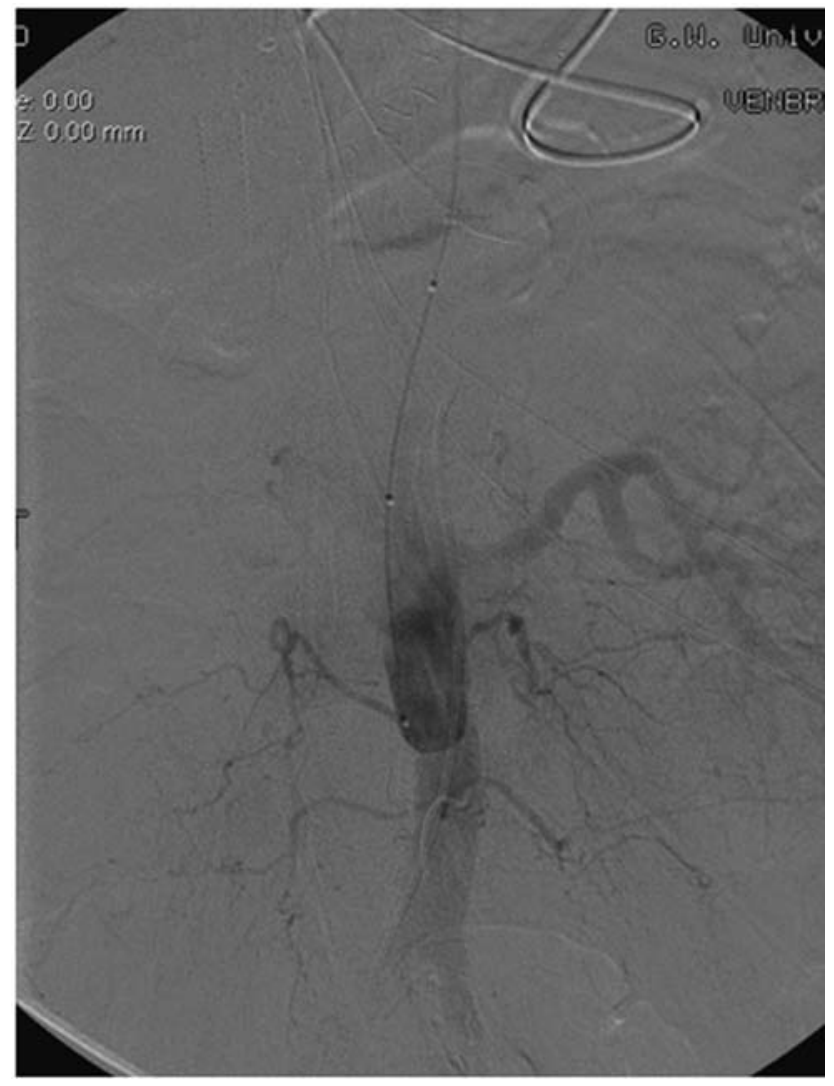

Fig. 7 Mesenteric and renal ischemia from aortic dissection. Aortogram with flush catheter in compressed true lumen supplying the left renal.

Roselli et $\mathrm{al}^{60}$ described three different techniques for the anterograde delivery of devices: axillary artery, ascending aorta, or direct placement. The main complications were stroke, spinal cord injury, respiratory failure, and renal failure. $^{61}$

\section{Renal Failure}

Although TEVAR avoids aortic cross-clamp or cardiopulmonary bypass, acute kidney injury (AKI) is still a common complication after TEVAR, ranging between 1 and $34 \% .{ }^{12}$ The wide range of variability is due to the lack of standardized definition for renal failure. ${ }^{63}$ Besides patient factors, such as hypertension and chronic renal failure that increases the risk of AKI, iodized contrast is widely accepted as a contributing factor of AKI. ${ }^{64}$ Preventive strategies, such as preoperative hydration and administering $\mathrm{N}$-acetylcysteine, have been widely used but with varying results. ${ }^{65}$

\section{Conversion to Open Repair}

The incidence of patients who require conversion to open thoracic aortic aneurysm repair from TEVAR has been reported to be 2.2 to $7.2 \%$ at experienced centers. ${ }^{66,67}$ In a retrospective study by Canaud et al, ${ }^{68} 14$ patients out of 236 required open surgical repair after TEVAR for retrograde Type A dissection, secondary aortobronchial fistula, stent-graft infection, aortoesophageal fistula, aneurysm enlargement, 
and stent-graft collapse. With the advent of TEVAR, it is even more important for clinicians to recognize situations that require rapid conversion to open repair.

\section{Conclusion}

TEVAR has transformed the prognosis for patients with thoracic aortic aneurysm and become the gold standard for elective thoracic aortic aneurysm repairs. While this article belabors the importance of understanding the wide range of TEVAR complications and limitations, it is also important to glance back in the history of aortic aneurysm repair and appreciate how far endovascular and open surgical techniques have advanced. With long-term follow-up data from TEVAR in the next decade, clinicians and engineers will be able to continue to refine endovascular technology and redefine the applications for endovascular techniques.

\section{Funding}

None.

\section{Conflict of Interest}

The authors declare no conflict of interest related to this article.

\section{Acknowledgments}

None.

\section{References}

1 Dake MD, Miller DC, Semba CP, Mitchell RS, Walker PJ, Liddell RP. Transluminal placement of endovascular stent-grafts for the treatment of descending thoracic aortic aneurysms. N Engl J Med 1994;331(26):1729-1734

2 Bavaria JE, Appoo JJ, Makaroun MS, Verter J, Yu ZF, Mitchell RS; Gore TAG Investigators. Endovascular stent grafting versus open surgical repair of descending thoracic aortic aneurysms in lowrisk patients: a multicenter comparative trial. J Thorac Cardiovasc Surg 2007;133(02):369-377

3 Dake MD, Miller DC, Mitchell RS, Semba CP, Moore KA, Sakai T. The "first generation" of endovascular stent-grafts for patients with aneurysms of the descending thoracic aorta. J Thorac Cardiovasc Surg 1998;116(05):689-703, discussion 703-704

4 Scali ST, Goodney PP, Walsh DB, et al. National trends and regional variation of open and endovascular repair of thoracic and thoracoabdominal aneurysms in contemporary practice. J Vasc Surg 2011;53(06):1499-1505

5 Yao JS, Eskandari MK, Parodia J. Transfemoral intraluminal graft implantation for abdominal aortic aneurysms, 1991: two decades later. Ann Vasc Surg 2012;26(07):895-905

6 Parodi JC, Palmaz JC, Barone HD. Transfemoral intraluminal graft implantation for abdominal aortic aneurysms. Ann Vasc Surg 1991;5(06):491-499

7 Gopaldas RR, Huh J, Dao TK, et al. Superior nationwide outcomes of endovascular versus open repair for isolated descending thoracic aortic aneurysm in 11,669 patients. J Thorac Cardiovasc Surg 2010;140(05):1001-1010

8 Makaroun MS, Dillavou ED, Kee ST, et al; GORE TAG Investigators. Endovascular treatment of thoracic aortic aneurysms: results of the phase II multicenter trial of the GORE TAG thoracic endoprosthesis. J Vasc Surg 2005;41(01):1-9

9 Singh MJ, Makaroun MS. Thoracic and thoraco-abdominal aneurysms: endovascular treatment. In: Sidawy AN, Perler AB, eds.
Rutherford's Vascular Surgery and Endovascular Therapy. 9th ed. Elsevier; 2019:1008-1024

10 Maurel B, Mastracc ITM. Thoracic and thoraco-abdominal aneurysms: aortic stent grafts and techniques of thoracic endovascular aortic repair. In: Sidawy AN, Perler AB, eds. Rutherford's Vascular Surgery and Endovascular Therapy. 9th ed. Elsevier; 2019: 1025-1035

11 Cooley DA. A brief history of aortic aneurysm surgery. Aorta (Stamford) 2013;1(01):1-3

12 Sattah AP, Secrist MH, Sarin S. Complications and perioperative management of patients undergoing thoracic endovascular aortic repair. J Intensive Care Med 2018;33(07):394-406

13 Hiratzka LF, Bakris GL, Beckman JA, et al; American College of Cardiology Foundation/American Heart Association Task Force on Practice Guidelines; American Association for Thoracic Surgery; American College of Radiology; American Stroke Association; Society of Cardiovascular Anesthesiologists; Society for Cardiovascular Angiography and Interventions; Society of Interventional Radiology; Society of Thoracic Surgeons; Society for Vascular Medicine. 2010 ACCF/AHA/AATS/ACR/ASA/SCA/SCAI/SIR/STS/ SVM guidelines for the diagnosis and management of patients with thoracic aortic disease: a report of the American College of Cardiology Foundation/American Heart Association Task Force on Practice Guidelines, American Association for Thoracic Surgery, American College of Radiology, American Stroke Association, Society of Cardiovascular Anesthesiologists, Society for Cardiovascular Angiography and Interventions, Society of Interventional Radiology, Society of Thoracic Surgeons, and Society for Vascular Medicine. Circulation 2010;121(13):e266-e369

14 Grabenwöger M, Alfonso F, Bachet J, et al. Thoracic endovascular aortic repair (TEVAR) for the treatment of aortic diseases: a position statement from the European Association for CardioThoracic Surgery (EACTS) and the European Society of Cardiology (ESC), in collaboration with the European Association of Percutaneous Cardiovascular Interventions (EAPCI). Eur Heart J 2012;33 (13):1558-1563

15 Honari G, Ellis SG, Wilkoff BL, Aronica MA, Svensson LG, Taylor JS. Hypersensitivity reactions associated with endovascular devices. Contact Dermat 2008;59(01):7-22

16 Rynio P, Kazimierczak A, Jedrzejczak T, Gutowski P. A 3-dimensional printed aortic arch template to facilitate the creation of physician-modified stent-grafts. J Endovasc Ther 2018;25(05): 554-558

17 Cheng D, Martin J, Shennib H, et al. Endovascular aortic repair versus open surgical repair for descending thoracic aortic disease a systematic review and meta-analysis of comparative studies. J Am Coll Cardiol 2010;55(10):986-1001

18 Acher C, Acher CW, Marks E, Wynn M. Intraoperative neuroprotective interventions prevent spinal cord ischemia and injury in thoracic endovascular aortic repair. J Vasc Surg 2016;63(06): $1458-1465$

19 Awad H, Ramadan ME, El Sayed HF, Tolpin DA, Tili E, Collard CD. Spinal cord injury after thoracic endovascular aortic aneurysm repair. Can J Anaesth 2017;64(12):1218-1235

20 Etz DC, Luehr M, Aspern KV, et al. Spinal cord ischemia in open and endovascular thoracoabdominal aortic aneurysm repair: new concepts. J Cardiovasc Surg (Torino) 2014;55(02, Suppl 1):159-168

21 Colman MW, Hornicek FJ, Schwab JH. Spinal cord blood supply and its surgical implications. J Am Acad Orthop Surg 2015;23(10): 581-591

22 Griepp RB, Griepp EB. Spinal cord protection in surgical and endovascular repair of thoracoabdominal aortic disease. J Thorac Cardiovasc Surg 2015;149(2, suppl):S86-S90

23 Khan NR, Smalley Z, Nesvick CL, Lee SL, Michael LM II. The use of lumbar drains in preventing spinal cord injury following thoracoabdominal aortic aneurysm repair: an updated systematic review and meta-analysis. J Neurosurg Spine 2016;25(03): 383-393 
24 Scali ST, Wang SK, Feezor RJ, et al. Preoperative prediction of spinal cord ischemia after thoracic endovascular aortic repair. J Vasc Surg 2014;60(06):1481-90.e1

25 Chang CK, Chuter TA, Reilly LM, et al. Spinal arterial anatomy and risk factors for lower extremity weakness following endovascular thoracoabdominal aortic aneurysm repair with branched stentgrafts. J Endovasc Ther 2008;15(03):356-362

26 Buth J, Harris PL, Hobo R, et al. Neurologic complications associated with endovascular repair of thoracic aortic pathology: Incidence and risk factors. A study from the European Collaborators on Stent/Graft Techniques for Aortic Aneurysm Repair (EUROSTAR) registry. J Vasc Surg 2007;46(06):1103-1110, discussion 1110-1111

27 Khoynezhad A, Donayre CE, Bui H, Kopchok GE, Walot I, White RA. Risk factors of neurologic deficit after thoracic aortic endografting. Ann Thorac Surg 2007;83(02):S882-S889, discussion S890S892

28 Etz CD, Debus ES, Mohr FW, Kölbel T. First-in-man endovascular preconditioning of the paraspinal collateral network by segmental artery coil embolization to prevent ischemic spinal cord injury. J Thorac Cardiovasc Surg 2015;149(04):1074-1079

29 Kakinohana M. What should we do against delayed onset paraplegia following TEVAR? J Anesth 2014;28(01):1-3

30 Uchida N. How to prevent spinal cord injury during endovascular repair of thoracic aortic disease. Gen Thorac Cardiovasc Surg 2014;62(07):391-397

31 Ullery BW, Cheung AT, Fairman RM, et al. Risk factors, outcomes, and clinical manifestations of spinal cord ischemia following thoracic endovascular aortic repair. J Vasc Surg 2011;54(03): 677-684

32 Teixeira PG, Woo K, Beck AW, Scali ST, Weaver FA; Society for Vascular Surgery, Vascular Quality Initiative (VQI)®. Association of left subclavian artery coverage without revascularization and spinal cord ischemia in patients undergoing thoracic endovascular aortic repair: a Vascular Quality Initiative analysis. Vascular 2017;25(06):587-597

33 Wong CS, Healy D, Canning C, Coffey JC, Boyle JR, Walsh SR. A systematic review of spinal cord injury and cerebrospinal fluid drainage after thoracic aortic endografting. J Vasc Surg 2012;56 (05):1438-1447

34 Schlösser FJ, Verhagen HJ, Lin PH, et al. TEVAR following prior abdominal aortic aneurysm surgery: increased risk of neurological deficit. J Vasc Surg 2009;49(02):308-314, discussion 314

35 Epstein NE. Cerebrospinal fluid drains reduce risk of spinal cord injury for thoracic/thoracoabdominal aneurysm surgery: a review. Surg Neurol Int 2018;9:48

36 Bischoff MS, Scheumann J, Brenner RM, et al. Staged approach prevents spinal cord injury in hybrid surgical-endovascular thoracoabdominal aortic aneurysm repair: an experimental model. Ann Thorac Surg 2011;92(01):138-146, discussion 146

37 Kasprzak PM, Gallis K, Cucuruz B, Pfister K, Janotta M, Kopp R. Editor's choice-Temporary aneurysm sac perfusion as an adjunct for prevention of spinal cord ischemia after branched endovascular repair of thoracoabdominal aneurysms. Eur J Vasc Endovasc Surg 2014;48(03):258-265

38 Lima B, Nowicki ER, Blackstone EH, et al. Spinal cord protective strategies during descending and thoracoabdominal aortic aneurysm repair in the modern era: the role of intrathecal papaverine. J Thorac Cardiovasc Surg 2012;143(04):945-952.e1

39 Feezor RJ, Martin TD, Hess PJ, et al. Risk factors for perioperative stroke during thoracic endovascular aortic repairs (TEVAR). J Endovasc Ther 2007;14(04):568-573

40 Desai ND, Pochettino A, Szeto WY, et al. Thoracic endovascular aortic repair: evolution of therapy, patterns of use, and results in a 10-year experience. J Thorac Cardiovasc Surg 2011;142(03):587-594

41 Hajibandeh S, Hajibandeh S, Antoniou SA, Torella F, Antoniou GA. Meta-analysis of left subclavian artery coverage with and without revascularization in thoracic endovascular aortic repair. J Endovasc Ther 2016;23(04):634-641
42 Voskresensky I, Scali ST, Feezor RJ, et al. Outcomes of thoracic endovascular aortic repair using aortic arch chimney stents in high-risk patients. J Vasc Surg 2017;66(01):9-20.e3

43 Lindblad B, Bin Jabr A, Holst J, Malina M. Chimney grafts in aortic stent grafting: hazardous or useful technique? Systematic review of current data. Eur J Vasc Endovasc Surg 2015;50(06):722-731

44 White GH, Yu W, May J, Chaufour X, Stephen MS. Endoleak as a complication of endoluminal grafting of abdominal aortic aneurysms: classification, incidence, diagnosis, and management. J Endovasc Surg 1997;4(02):152-168

45 van Marrewijk C, Buth J, Harris PL, Norgren L, Nevelsteen A, Wyatt MG. Significance of endoleaks after endovascular repair of abdominal aortic aneurysms: The EUROSTAR experience. J Vasc Surg 2002;35(03):461-473

46 Alsac JM, Khantalin I, Julia P, et al. The significance of endoleaks in thoracic endovascular aneurysm repair. Ann Vasc Surg 2011;25 (03):345-351

47 Terzi F, Rocchi G, Fattori R. Current challenges in endovascular therapy for thoracic aneurysms. Expert Rev Cardiovasc Ther 2016;14(05):599-607

48 Chen J, Stavropoulos SW. Management of Endoleaks. Semin Intervent Radiol 2015;32(03):259-264

49 Maldonado TS, Rosen RJ, Rockman CB, et al. Initial successful management of type I endoleak after endovascular aortic aneurysm repair with n-butyl cyanoacrylate adhesive. J Vasc Surg 2003;38(04):664-670

50 Biasi L, Ali T, Hinchliffe R, Morgan R, Loftus I, Thompson M. Intraoperative DynaCT detection and immediate correction of a type Ia endoleak following endovascular repair of abdominal aortic aneurysm. Cardiovasc Intervent Radiol 2009;32(03):535-538

51 Thomas BG, Sanchez LA, Geraghty PJ, Rubin BG, Money SR, Sicard GA. A comparative analysis of the outcomes of aortic cuffs and converters for endovascular graft migration. J Vasc Surg 2010;51 (06):1373-1380

52 Hinchliffe RJ, Krasznai A, Schultzekool L, et al. Observations on the failure of stent-grafts in the aortic arch. Eur J Vasc Endovasc Surg 2007;34(04):451-456

53 Smith ST, Clagett GP, Arko FR. Endovascular conversion with femorofemoral bypass as a treatment of endotension and aneurysm sac enlargement. J Vasc Surg 2007;45(02):395-398

54 Kougias P, Lin PH, Dardik A, Lee WA, El Sayed HF, Zhou W. Successful treatment of endotension and aneurysm sac enlargement with endovascular stent graft reinforcement. J Vasc Surg 2007;46(01):124-127

55 Muhs BE, Balm R, White GH, Verhagen HJ. Anatomic factors associated with acute endograft collapse after Gore TAG treatment of thoracic aortic dissection or traumatic rupture. J Vasc Surg 2007;45(04):655-661

56 Kasirajan K, Dake MD, Lumsden A, Bavaria J, Makaroun MS. Incidence and outcomes after infolding or collapse of thoracic stent grafts. J Vasc Surg 2012;55(03):652-658, discussion 658

57 Jordan WD Jr, Mehta M, Varnagy D, et al; Aneurysm Treatment using the Heli-FX Aortic Securement System Global Registry (ANCHOR) Workgroup Members. Results of the ANCHOR prospective, multicenter registry of EndoAnchors for type Ia endoleaks and endograft migration in patients with challenging anatomy. J Vasc Surg 2014;60(04):885-92.e2

58 Tadros RO, Lipsitz EC, Chaer RA, Faries PL, Marin ML, Cho JS. A multicenter experience of the management of collapsed thoracic endografts. J Vasc Surg 2011;53(05):1217-1222

59 Yano OJ, Faries PL, Morrissey N, Teodorescu V, Hollier LH, Marin ML. Ancillary techniques to facilitate endovascular repair of aortic aneurysms. J Vasc Surg 2001;34(01):69-75

60 Roselli EE, Soltesz EG, Mastracci T, Svensson LG, Lytle BW. Antegrade delivery of stent grafts to treat complex thoracic aortic disease. Ann Thorac Surg 2010;90(02):539-546

61 van Bogerijen GHW, Williams DM, Eliason JL, Dasika NL, Deeb GM, Patel HJ. Alternative access techniques with thoracic endovascular 
aortic repair, open iliac conduit versus endoconduit technique. J Vasc Surg 2014;60(05):1168-1176

62 Vandy FC, Girotti M, Williams DM, et al. Iliofemoral complications associated with thoracic endovascular aortic repair: frequency, risk factors, and early and late outcomes. J Thorac Cardiovasc Surg 2014;147(03):960-965 [serial online]

63 Jeon $\mathrm{YH}$, Bae $\mathrm{CH}$. The risk factors and outcomes of acute kidney injury after thoracic endovascular aortic repair. Korean J Thorac Cardiovasc Surg 2016;49(01):15-21

64 Drews JD, Patel HJ, Williams DM, Dasika NL, Deeb GM. The impact of acute renal failure on early and late outcomes after thoracic aortic endovascular repair. Ann Thorac Surg 2014;97(06):2027-2033, discussion 2033
65 Azzalini L, Spagnoli V, Ly HQ. Contrast-induced nephropathy: from pathophysiology to preventive strategies. Can J Cardiol 2016;32(02):247-255

66 Dumfarth J, Michel M, Schmidli J, et al. Mechanisms of failure and outcome of secondary surgical interventions after thoracic endovascular aortic repair(TEVAR). Ann Thorac Surg 2011;91(04):1141-1146

67 Girdauskas E, Falk V, Kuntze T, et al. Secondary surgical procedures after endovascular stent grafting of the thoracic aorta: successful approaches to a challenging clinical problem. J Thorac Cardiovasc Surg 2008;136(05):1289-1294

68 Canaud L, Alric P, Gandet T, Ozdemir BA, Albat B, Marty-Ane C. Open surgical secondary procedures after thoracic endovascular aortic repair. Eur J Vasc Endovasc Surg 2013;46(06):667-674 